\section{Disciplina, corpo e discurso na publicidade de produtos para cabelos cacheados}

\author{
Discipline, body and discourse \\ in the advertising of products \\ for curly hairs
}

Graça Regina Braga CAMPOS (UFMA) camposgraca27@gmail.com Mônica da Silva CRUZ (UFMA) monicasc.cruz@ig.com.br

Recebido em: 13 de jan. de 2018. Aceito em: 07 de jun. de 2018.
CAMPOS, Graça Regina Braga;

CRUZ, Mônica da Silva. Disciplina, corpo e discurso na publicidade de produtos para cabelos cacheados. Entrepalavras, Fortaleza, v. 8, n. 2, p. 120-136, maio/ago. 2018

Resumo: Neste artigo, analisa-se uma série enunciativa de anúncios publicados em sítios eletrônicos que promovem cabelos cacheados. Busca-se entender como normas de beleza dos cabelos trazem enunciados que remetem a discursos outros, situados nos fios da memória da história do Brasil, país constituído em grande medida por uma população negra que, desde o período da colonização, teve como referência mais forte a beleza branca. Com base nos estudos de Michel Foucault (1999) sobre o poder disciplinar, corpo e discursos (FOUCAULT, 2012), analisa-se, nesses anúncios, a retomada de uma memória sobre os cabelos lisos e não lisos, na atualidade, momento em que são recorrentes discursos que valorizam a diversidade e a multiplicidade étnica. A seleção dos enunciados foi realizada por consulta em um site de busca, a partir da expressão "cabelos cacheados". Os resultados das análises mostram que nesses enunciados existem regras de disciplinamento sobre o uso dos cabelos cacheados, pautadas em uma memória, ainda muito viva na cultura brasileira, a qual propõe como referência adequada de beleza as formas dos cabelos lisos, principalmente do liso de matriz cultural branca.

Palavras-chave: Disciplina. Corpo. Discurso. 
Abstract: This article analyzes an enunciative series of advertisements on eletronic sites that promote curly hair. It seeks to understand how norms of beauty of hair bring statements that refer to other discourses, located in the memory of Brazil, a country largely constituted by a black population and that, since the period of colonization, had as strongest reference to white beauty based on Michel Foucault's (1999) studies on the disciplinary power, body and speeches (FOUCAULT, 2012), we analyze in these ads the resumption of a memory about straight and nor straigh hair, at the moment, when are recurrent discourses that value diversity and ethnic multiplicity. The selection of the utterances was done by consulting a searche site, using the expression "curly hair". The results of the analyzes show that in these statements there are rules of discipline on the use of curly hair, based on a memory, still very much alive in Brazilian culture, which proposes as an appropriate reference for beauty the sha pes of straight hair, cultural white.

Keywords: Discipline. Body. Speech.

\section{Introdução}

A história mostra que a construção do belo, em matéria de corpo, sempre foi modelada por poderes e saberes que ditam o que é considerado feio ou bonito, em diferentes épocas e sociedades. Assim, compreende-se por que, em dado momento, um padrão de beleza corporal é eleito e, em seguida, outro conceito entra em cena para significar o belo.

O corpo, por diferentes razões, aos poucos se constituiu em espaço de inscrição de poderes. Michel Foucault (1999), em Vigiare Punir, realizou investigação significativa sobre formas de exercício do poder que se inscrevem nos corpos, considerando um momento da história ocidental - o início do século XVIII. Esse tipo de poder, que nascia gradativamente, foi chamado pelo autor francês de "poder disciplinar", um poder difuso, que se exerce sobre os corpos dos indivíduos, de forma sutil, normalmente, para transformá-los em força produtiva e aptos a obedecer às vontades do poder.

Neste artigo, tomam-se como aparato teórico alguns princípios foucaultianos a respeito do poder disciplinar para análise do funcionamento discursivo de publicidades que, ao proporem a mulheres o uso dos cabelos cacheados como padrão de beleza, acionam discursos outros, situados nos fios da memória da história do Brasil, país que é constituído em grande medida por uma população negra, mas que, desde o período da sua colonização, teve como forte referente de beleza matrizes culturais brancas. O objetivo específico do trabalho é analisar uma série enunciativa de anúncios publicados em sites e discutir como normas de beleza de usos dos cabelos femininos se apoiam em discursos 
V. 8 (2)

$120-136$

mai/ago 2018

dispersos na constituição histórica e cultural do país. A relevância da pesquisa está em observar como o poder disciplinar retoma, pelo viés enunciativo, memórias sobre os cabelos lisos e não lisos, na atualidade, momento em que são recorrentes no país discursos que valorizam a diversidade e a multiplicidade de etnias.

O artigo divide-se nas seguintes partes: apresenta-se inicialmente uma síntese do olhar de Foucault sobre a emergência do poder disciplinar. Em seguida, faz-se um sucinto levantamento histórico, que permite perceber como os cabelos tornaram-se ícone de pertencimento social. Posteriormente, analisa-se como, na esfera discursiva, a indústria de cosméticos capilar e a publicidade estabelecem normas de disciplinamento ao cabelo cacheado da mulher afrobrasileira ${ }^{1}$, a partir de uma memória ligada aos cabelos lisos.

\section{Corpo, poder e disciplina}

Numa breve retomada sobre o disciplinamento do corpo, descobre-se em Foucault (1999) que, no século XVII, o exército exigia dos soldados uma postura erétil, que simbolizasse o vigor, a coragem, as marcas de orgulho do homem militar, o que, mais tarde, passa a servir de parâmetro para o adestramento corporal em várias esferas sociais.

Esse disciplinamento transformou o corpo do soldado numa espécie de "máquina humana"; num material fabricado em série, em que se corrigia aos poucos a postura. Segundo Foucault (1999, p. 117), estabelecia-se lentamente uma coerção calculada, que percorria cada parte do corpo, assenhorava-se dele, dobrava-lhe o conjunto, tornava-o perpetuamente disponível, e se prolongava, em silêncio, no automatismo dos hábitos. Tudo isso consistia em normas de adestramento físico.

A partir desse período, o corpo é descoberto como um objeto de poder, que deveria ser modelado, manipulado, obediente e dócil. Para Foucault (1999, p. 118), é "dócil um corpo que pode ser submetido, que pode ser utilizado, que pode ser transformado e aperfeiçoado." Esse poder de manipulação vai ser promovido pelas técnicas da disciplina.

Além dos exercícios de alinhamento postural, uma das técnicas que facilitavam o disciplinamento do corpo social consistia na separação dos indivíduos em espaços específicos. Então, com base no modelo do exército, o corpo passa a ser moldado também nas escolas,

${ }^{1}$ Entende-se neste trabalho afro-brasileira a mulher brasileira de ascendência africana. 
nos reformatórios, nos conventos, nas igrejas, nas fábricas, e, até nos hospitais. Nesses espaços, os indivíduos eram separados pela conduta, pelas habilidades (ou falta destas), pelo vigor físico, pela condição financeira, enfim, por tudo que pudesse diferenciar um grupo de outro e assim classificá-los e adestrá-los. Sobre essas estratégias, Foucault (1999, p. 123) afirma:

[...] importa estabelecer as presenças e ausências, saber onde e como encontrar os indivíduos, instaurar as comunicações úteis, interromper as outras, poder a cada instante vigiar o comportamento de cada um, apreciá-lo, sancioná-lo, medir as qualidades ou os méritos.

A distribuição dos indivíduos em espaços institucionalizados facilitaria, então, o processo de coerção, manipulação e disciplinamento do indivíduo. O corpo, nesse período, era disciplinado a partir de ordens e normas explicitamente estabelecidas por aquelas instituições.

Vale lembrar que o desejo em disciplinar o corpo vem de tempos mais remotos ainda, porém, os objetivos de ajustamento não eram os mesmos que os da esfera militar. Segundo Vieira e Souza (2002, p.134), encontram-se registros das exigências de postura do corpo em Cícero (143-103 a.C.) e Santo Ambrósio (340-397 d.C.). Esses autores defendiam os parâmetros definidores dos gestos, os quais, bons ou maus, eram a razão humana da vontade de Deus.

Da era clássica à modernidade, percebe-se maior dispersão dos espaços disciplinares de controle sobre o corpo, pois a vigília amplia-se para vários setores sociais, além dos já citados. Dessa forma, estabelecem-se ações disciplinares promovidas pelo que Michel Foucault denomina de micropoder. Assim, a disciplina passa a ser conduzida de forma mais sutil, menos explícita, determinada por práticas sociais que se enraízam e permitem que o adestramento seja imperceptível aos olhos do adestrado. Questionado sobre a existência dos poderes e micropoderes, o autor francês explica:

É um conjunto extremamente complexo sobre o qual somos obrigados a perguntar como ele pode ser tão sutil em sua distribuição, em seus mecanismos, em seus controles recíprocos, em seus ajustamentos, se não há quem tenha pensado o conjunto. É um mosaico muito complicado. Em certos períodos aparecem agentes de ligação (...). Tomemos o exemplo da filantropia no início do século XIX: pessoas que vêm se ocupar da vida dos outros, de sua saúde, da alimentação, da moradia... Mais tarde, dessa função confusa sairiam personagens, instituições, saberes [...] (FOUCAULT, 2015, p. 243). 
V. $8(2)$

$120-136$

mai/ago 2018

Então, concomitante ao disciplinamento da postura erétil, do corpo forte e austero, herdado do exército; do disciplinamento físico e intelectual, imposto pelas escolas; do corpo moral e ético, exigido pela religião e pela justiça, surgem na sociedade os micropoderes, gerados por grupos menores, de vertentes múltiplas. Na contemporaneidade, é possível observar essa disciplina agindo de várias maneiras, tanto em termos de saúde quanto em termos de estética corporal. Nesse último caso, há micropoderes que determinam normas disciplinares corporais a partir de detalhes sobre a vestimenta, o uso de adereços, a dieta para a alimentação, os exercícios físicos, o uso de cosméticos, e, dentre estes últimos, a estética de beleza dos cabelos. Para Foucault (1999), esse disciplinamento dos corpos tem eficácia muitas vezes mais acentuada que outras formas de poder, porque ele é ativado por meio de práticas discursivas e não-discursivas que se espalham em todos os espaços sociais, de forma discreta, sem reprimir os sujeitos explicitamente.

\section{O cabelo como ícone de pertencimento social}

Na visão de Michel Foucault, as práticas sociais de uma época resultam de discursos eivados de poderes, que se dispersam e constituem o sujeito, em todos os níveis da sua existência, inclusive em seus corpos, conforme apontado anteriormente. Gomes (2006, p. 264), nessa mesma linha, esclarece que o corpo pode ser ordenado em suas diferentes dimensões, entre elas, o cabelo. Portanto, as práticas sociais (discursivas e não discursivas) que definem o que é um cabelo bonito não escapam desse movimento, conforme explicita-se no breve histórico a seguir.

Algumas pesquisas demonstram que a manipulação do cabelo como forma de disciplinamento do corpo é bastante antiga. Para Gomes (2006, p. 158-159), manter o cabelo limpo e em "ordem", por exemplo, era uma maneira de disciplinamento corporal.

De acordo com Quintão (2013, p. 14), os primeiros registros sobre a manipulação dos cabelos são encontrados na história da sociedade do Antigo Egito, assim como na sociedade judaica e muçulmana. Os antigos egípcios já apresentavam preocupação com a aparência dos fios: para exibir beleza, usavam tranças, perucas e realizavam técnicas de tingimento, pois, os cabelos, para eles, eram um sí mbolo de poder, ostentação e boa aparência. 
Para os judaicos e muçulmanos, o cabelo simbolizava a sedução feminina, por isso, uma tentação aos olhos masculinos (QUINTÃO, 2013, p. 14). As mulheres desses povos primavam pelos fios longos; quanto maiores, mais atraentes eram consideradas. Contudo, por questões religiosas, elas os mantinham cobertos; cabia apenas ao marido o direito de olhá-los e tocá-los.

Nos séculos XVII e XVIII, o cabelo é concebido como item de moda, e seguir a moda, nessa época, já era dispendioso. Por isso, a aparência dos cabelos da mulher indicava a condição financeira do marido, de seu status de pertencimento social. Quanto mais brilhosos, sedosos e bem tratados, maior era a condição econômica do senhor da casa. Devido a isso, a autora explica que o cabelo pertence tanto à esfera da vida privada, quanto da vida pública, já que é a sociedade que dita as normas estéticas de uso dos fios, cabendo aos indivíduos segui-las, caso queiram ser aceitos socialmente (QUINTÃO, 2013, p.15-16).

A autora acentua, que em razão do prestígio cultural e econômico, o cabelo liso e loiro do europeu branco tornou-se parâmetro para uma estética "positiva", de representação simbólica de poder, haja vista que a Europa foi responsável pelo domínio econômico mundial durante muitos séculos, e, consequentemente pelo domínio cultural dos povos escravizados.

Nessa perspectiva de simbologia de poder do cabelo liso e loiro, o cabelo do negro afrodescendente torna-se característica física não aceitável, por estar fora dos padrões de beleza estabelecidos pelo branco europeu, e, mais que isso, por ser um item fenotípico de uma raça considerada inferior, devido às condições de escravidão em que foi colocada. Um ideal ainda muito presente nos dias atuais.

Devido à posição de padrão de beleza em que os cabelos lisos do europeu foram colocados, estes se tornam objeto de desejo de afrodescendentes. No período colonial, por exemplo, em que a escravidão ainda era forte nos países americanos, o desejo em adquirir respeito e aceitação social fazia com que filhos de homens brancos com escravas buscassem técnicas de alisamentos dos cabelos, pois já que nasciam com pele mais clara, queriam parecer brancas para esconder sua outra etnia e passar por pessoas livres (QUINTÃO, 2013, p. 17). Segundo Braga (2008, p. 82), as representações estéticas inspiradas no modelo de beleza europeu após a escravidão passam a figurar como objeto de desejo dos negros, daí a prática de alisar os cabelos. 
V. 8 (2)

$120-136$

mai/ago 2018

Então, para alcançar a imagem idealizada, muitas mulheres negras e afrodescendentes começaram a busca por técnicas de alisamento dos fios. Com isso, mais tarde, surge nos Estados Unidos o movimento do Novo Negro, promovido por algumas dessas mulheres, que conseguiram ascender socialmente, pois

o cabelo farto e alisado se tornara um indicador da negra da classe média negra norte-americana, já que havia a crença de que com cabelo curto, crespo ou falho uma mulher negra teria dificuldades para alcançar sua integração socioeconômica (QUINTÃO, 2013, p. 18-19).

Dentre as técnicas criadas, um uso corrente entre as mulheres afrodescendentes americanas e, posteriormente, as brasileiras, era o pente de ferro quente nos cabelos, para eliminar os crespos e os cachos. Era uma espécie de chapinha ${ }^{2}$ da era colonial. Elas usavam também banha de porco, para deixar os cabelos mais sedosos e brilhosos.

Com base nessas informações, observa-se que, do período colonial até a atualidade, essas técnicas foram se aperfeiçoando. Frisase que, em vista de fatores como o fortalecimento de uma indústria de cosméticos capilar brasileira e o crescimento da circulação dos meios de comunicação, houve grande difusão de modelos de cabelos considerados esteticamente belos, em práticas sociais que dão grande destaque aos fios lisos. Porém, conforme Foucault (2012), todo conceito é histórico, tende a se transformar, associa-se a outros conceitos e a poderes de distintas ordens.

Nesse âmbito, recentemente, com a proliferação de discursos como o da diversidade cultural, ou mesmo da inclusão social, é notória a propagação de cabelos cacheados ou crespos, antes postos à margem de um conceito de beleza, no Brasil. Isso ocorre em vários espaços discursivos, como nas mídias, de modo geral, mas também nas artes, ou mesmo nas ciências.

No próximo item, discute-se como historicamente irromperam acontecimentos que propiciaram o surgimento de um conceito de beleza que incluiu os cabelos cacheados como um padrão a ser valorizado na cultura brasileira.

\footnotetext{
${ }^{2}$ A chapinha é um aparelho feito de plástico e cerâmica que, conectado à tomada elétrica, esquenta, assim como um ferro de passar roupas. É utilizada para dar um efeito liso aos cabelos.
} 


\section{A beleza dos cabelos da mulher brasileira: do liso aos cachos}

Em artigo sobre as técnicas de alisamento dos cabelos no Brasil, publicado na revista Cabelo\&Cia, de autoria de Santos (2015), relata-se que por volta de 1930 ainda não existiam alisantes químicos, mas o padrão dos cabelos lisos tinha grande influência entre as brasileiras. Nessa época, era usado um aparelho chamado cabelisador (também uma espécie de chapinha para cabelos). Já na década de 1940, o pente quente começa a ser usado no Brasil, alguns anos depois que as americanas passaram a usar. Esse pente de ferro era aquecido no fogo em brasa e aplicado sobre os cabelos para alongá-los.

Segundo o estudo, é durante os anos de 1950 que o primeiro creme alisante começa a ser comercializado no país: o hidróxido de sódio, conhecido também como soda cáustica. Esse produto foi criado em 1914, mas foi somente naquela década que as mulheres afrodescendentes brasileiras passaram a usá-lo. A comercialização começou nos Estados Unidos.

Santos (2015) informa que, nas décadas de 1960 e 1970, os produtos para alisamento foram deixados um pouco de lado. Isso ocorre devido às descobertas de que a soda cáustica causava a perda excessiva dos cabelos, mas isso não eliminou o desejo de muitas mulheres em ter um cabelo liso e brilhoso. Para conseguir um efeito alisado, as mulheres passaram a usar toucas noturnas com grampos para fixar os cabelos. Essa técnica era conhecida como "caracol", por causa da forma como os cabelos eram enrolados.

Vaughan (2000) traça uma espécie de linha do tempo em relação aos estilos de cabelos mais acessados por negros em algumas décadas. Segundo a autora, na década de 1970, durante o movimento hippie, surge a moda dos cabelos naturais. As pessoas que seguiam esse movimento promoviam a imagem do corpo sem mudanças estéticas. Nesse período, o aspecto volumoso dos cabelos dos negros deu nome ao estilo Black Power, e, para destacar ainda mais esse volume, os homens, principalmente, usavam um pente semelhante ao garfo. Foi uma época em que a espontaneidade e o orgulho do cabelo negro dominavam o cenário social.

Nos anos 1980, a moda também promove o cabelo volumoso, mas, de todos os tipos de fios. Com inspiração nesse estilo, acontece no Brasil um movimento de inversão do liso, pois, com o desejo de dar volume aos cabelos, e estar na moda, mulheres de todas as etnias aderem ao uso dos já conhecidos bobs e bigudins. Porém, o alisamento 
v. $8(2)$

$120-136$

mai/ago 2018 continuou existindo, e para adquirir um cabelo linear, além dos alisantes, as mulheres usavam uma touca de gesso feita com uma mistura de farinha de trigo e tioglicolato de amônio. É nesse período também que surge a expressão relaxamento.

Dos anos 1990 até 2010, o estilo liso dos cabelos cresce com muita força. São criadas novas denominações para os processos de alisamento, tais como: escova progressiva, escova turca, chapinha, escova definitiva, Botox capilar. Mais tarde, a ciência descobre que os componentes químicos que compunham muitos desses produtos poderiam causar danos aos cabelos e à saúde. Então, os órgãos de controle da saúde começam a proibir esses alisantes. Essa proibição deveu-se ao excesso de formol na composição dos cremes, que poderia causar alergias sérias e até doenças mais graves como o câncer.

A partir desses estudos, pressupõe-se que a mulher afrobrasileira deixa de usar os alisantes químicos com receio de perder os cabelos e/ou comprometer a saúde. Mas a busca por alternativas que mantivessem o brilho, o movimento e o aspecto sedoso continuou. Percebendo isso, a indústria de cosméticos investe fortemente em produtos, como cremes menos agressivos, mas que mantêm o cabelo sob um regime de disciplinamento rigoroso, bastando, para isso, conferirem-se os rótulos de produtos capilares ou propagandas desse segmento.

Agindo, pois, de forma tentacular e com extrema sutileza, observa-se que a indústria de cosméticos opera um poder que está sempre vigiando e produzindo desejos individuais, propondo uma imagem ideal de beleza. Esse poder é mantido e reforçado por discursos promovidos pela mídia, que faz uma espécie de "ponte" entre essa indústria e a sociedade. Thompson (2009) concebe a mídia como uma instituição de poder simbólico, cuja ação acontece, também, simbolicamente. Para esse autor (2009, p. 24):

[...] A atividade simbólica é característica fundamental da vida social, em igualdade de condições com atividade produtiva, [...]. Os indivíduos se ocupam constantemente com as atividades de expressão de si mesmos em formas simbólicas ou de interpretação das expressões usadas pelos outros; eles são continuamente envolvidos na comunicação uns dos outros e na troca de informação de conteúdo simbólico (THOMPSON, 2009, p. 24).

Nessa concepção, os discursos de promoção dos cabelos cacheados não apenas apresentam estilos de cabelos para as mulheres 
como estabelecem um controle e uma disciplina dos fios, por meio de técnicas de persuasão, que influenciam o desejo de conquista de uma aparência dos cabelos que é aceita individual e socialmente. Assim, ao mesmo tempo em que a indústria de cosméticos e a mídia promovem o uso dos cabelos crespos e cacheados, elas, também, ditam normas de como esses cachos devem ser apresentados.

O campo publicitário, o qual usa as mídias para propagar um produto, comporta-se como porta-voz do discurso da indústria cosmética, estabelecendo que, além de sedosos e brilhosos, os cabelos devem ter flexibilidade, devem balançar durante o caminhar ou com a ajuda do vento. Por essa ótica, os cabelos que não têm movimento são geralmente caracterizados como "duros", e não pertencem ao padrão de beleza, pois a pouca flexibilidade é característica biológica do cabelo do negro.

Então, para resolver o "problema" do balanço, do "amolecimento" dos cabelos, a indústria de cosméticos investe fortemente em cremes para pentear, para dar ao cabelo um efeito flexível. Sobre esse aspecto, esta pesquisa propõe uma análise de enunciados que promovem os cabelos cacheados. Avaliam-se práticas discursivas que objetivam levar pessoas, na maioria mulheres, a usarem produtos que deixam os cachos com a imagem de um cabelo "comportado", disciplinado.

Para esse fim, selecionaram-se, em um site de busca, alguns enunciados em que é possível localizar práticas discursivas utilizadas para convencer mulheres de cabelos cacheados de que os fios devem ser disciplinados, devem seguir um padrão de beleza para esse tipo de cabelo. As práticas discursivas são elementos ligados ao conceito de discurso. Em perspectiva pós-saussureana, para Foucault (2012, p. 55), o discurso não é um conjunto de signos que remetem a representações ou a conteúdos, pois eles, os signos são práticas que criam as coisas. Foucault considera que o discurso é um conjunto de enunciados que não apenas designam as coisas, eles produzem-nas, como "práticas que formam de maneira sistemática os objetos de que falam". Os signos fazem muito mais que nomear as coisas e é esse "mais" que é preciso descrever.

Assim, é necessário analisar as regras de formação discursiva, regras que explicam um modo de produção dos objetos, das modalidades enunciativas, dos conceitos e dos temas/teorias (ou estratégias) que permitem o surgimento de um saber. O que está em jogo são as leis de 
V. $8(2)$

$120-136$

mai/ago 2018

construção das proposições que fazem um objeto existir, avaliando-se suas condições históricas de emersão. Conforme o autor, para esse tipo de análise do objeto é preciso "demarcar as superfícies primeiras de sua emergência: mostrar onde [elas] podem surgir, para que possam em seguida ser designadas e analisadas (...)" (FOUCAULT, 2012, p. 46).

Nesse aspecto, propõe-se a seguir a análise de uma "série enunciativa" (FOUCAULT, 2012, p.11), isto é, um conjunto de enunciados que se ligam por relações que coexistem em múltiplos acontecimentos. Essa série é composta por quatro blocos de anúncios de produtos para cabelos com cachos, de distintas marcas, localizados nos sites pesquisados. Esses enunciados foram selecionados a partir da busca "cabelos cacheados" e, embora componham textos de natureza multimodal, na série, analisa-se apenas a materialidade linguísticodiscursiva.

\section{Algumas análises}

O primeiro bloco de enunciados que se toma para análise é de uma marca que propõe em um dos seus produtos: CACHOS mais DISCIPLINADOS e, em outro: CABELOS mais ENCORPADOS ${ }^{3}$. Nesse âmbito, destacam-se algumas significações que emergem dos adjetivos disciplinados e encorpados. Nota-se que um poder disciplinar é exercido sobre os usos dos cabelos, por meio dessas palavras, já que os seus significados remetem ao que é alinhado, não "rebelde". Se a ideia de "disciplinado" refere-se ao cabelo que deve ser dominado, o termo "encorpado", em sites voltados para o cuidado dos cabelos crespos e cacheados, liga-se ao cabelo que não pode ser volumoso, pois o volume dá gera um efeito "inadequado" aos fios.

Em meio aos discursos que promovem cabelos cacheados, também surgem palavras que indicam a aparência "indesejável" dos cabelos, dentre estes, o conhecido frizz. Chamam-se frizz, no Brasil, os fios arrepiados, que dão um aspecto desalinhado aos cabelos. Por isso, devem ser evitados, como pode ser observado em outro anúncio. A frase em que a palavra frizz surge é: "Fique livre do frizz". Porém, a palavra frizz, segundo Olinto (2008), no Novo Dicionário Ilustrado de Inglês-Português, significa: cacho, ondulação, anel de cabelos frisados; encrespar ou frisar. Entende-se, então, que se livrar do frizz é livrar-se

${ }^{3}$ Não empregamos a forma gráfica fiel do anúncio, disponível no Google Imagens, por restrições de direitos de marca. 
dos crespos e dos cachos. Dessa forma, pode-se supor que a palavra é aplicada como um eufemismo, pois, frizz, na língua inglesa, idioma de origem do vocábulo, refere-se a cabelos anelados, frisados, formas que o produto tenta apagar. Sobre esses efeitos de ressignificação, podese notar a operação de um micropoder, que, nas palavras de Foucault (1999, p.120), refere-se a:

\begin{abstract}
Pequenas astúcias dotadas de um grande poder de difusão, arranjos sutis, de aparência inocente, mas profundamente suspeitos, dispositivos que obedecem a economias inconfessáveis, ou que procuram coerções sem grandezas [...]. Astúcias, não tanto de grande razão que trabalha até durante o sono e dá um sentido ao insignificante, quanto da atenta "malevolência" que de tudo se alimenta. A disciplina é uma anatomia política do detalhe.
\end{abstract}

Analisando-se a utilização desses "signos" linguísticos, entende-se que o poder disciplinar está infiltrado nas mínimas práticas, nos detalhes do cotidiano. Por isso, o sujeito não percebe na maioria das vezes que é modelado, vigiado, levado a uma subjetividade que é pertinente ao poder manter. Consoante Ortega (2007, p. 49), não se sabe o que se sente como sujeito disciplinado, "os corpos disciplinados não parecem sentir medo, frustração, dor, vergonha, humilhação, infelicidade ou ansiedade."

Outro nome que expressa imposição à disciplina dos cabelos é a palavra controle, que aparece em muitos comerciais de cremes para pentear ou hidratar. Controlar, nesse contexto, é não permitir que os cabelos apareçam desalinhados e com um aspecto ressecado. Controlar é manter os cachos bem "comportados", de acordo com o enunciado verbal de um anúncio de uma marca bem conhecida, a qual propõe, pelo uso do produto, um "Controle Supremo." Nesse enunciado, cabe analisarmos a palavra "controle" em consonância com a ideia de controle, proposta por Foucault.

O controle, na obra Vigiar e Punir, de Foucault (1999, p. 117), aparece como um dos indicadores de vigilância do corpo social, pois, nas fábricas, a vigilância era aplicada como "operador econômico decisivo, na medida em que é ao mesmo tempo uma peça interna no aparelho de produção e uma engrenagem específica do poder de disciplinar". Nesse sentido, é possível comparar a vigilância feita aos operários daquelas fábricas à vigilância da estética dos cabelos das mulheres afro-brasileiras atualmente, pois, ao mesmo tempo em que a indústria e a mídia demonstram "valorização" das características fenotípicas 
V. $8(2)$ $120-136$ mai/ago 2018 da cultura negra, elas mantêm e disciplinam a estética capilar dessas mulheres. Segundo Gomes (2008, p. 15), o cabelo é uma das marcas mais acentuadas das etnias no Brasil; é considerado uma linguagem que comunica e informa sobre as relações raciais.

Outros produtos elaborados para manter a disciplina dos cachos são os cremes de hidratação. De acordo com o discurso publicitário, servem para dar "vida", brilho, maciez e flexibilidade aos fios. O propósito de disciplinamento dos fios é tão acentuado, que muitas vezes está "estampado" em muitos rótulos e cartazes de venda de alguns desses produtos, que destacam "Cachos Disciplinados".

Impor sanções sobre o corpo, segundo Foucault (1999, p. 150), também é uma forma de punir. Punir, para esse autor, não é somente aplicar castigos que causam dor física, trata-se de repressões, por vezes, bastante sutis. No caso desta análise, verifica-se que a punição pode ser estabelecida no momento em que o discurso de poder da cultura branca, por exemplo, se impõe diante da identidade do corpo negro, e obriga-o, de forma muitas vezes velada, que este assuma uma identidade que não lhe pertence, uma identidade construída a partir dos preceitos da cultura do branco. Ainda sobre o poder, Foucault (2015, p. 278-279) considera que

[...] em uma sociedade como a nossa, mas no fundo em qualquer sociedade, existem relações de poder múltiplas que atravessam, caracterizam e constituem o corpo social e que essas relações de poder não podem se dissociar, se estabelecer nem funcionar sem uma produção, uma acumulação, uma circulação e um funcionamento do discurso. [...]

Foucault (1999, p. 161) ressalta que "o indivíduo é sem dúvida uma realidade fabricada por uma tecnologia específica de poder que se chama "disciplina"." Mas, ele defende que é preciso deixar de ver sempre o lado negativo do poder, pois, apesar de excluir, reprimir, recalcar, censurar, esconder e mascarar, esse poder também constrói realidades. A respeito dessa subjetividade fabricada, Czermak e Silva (2004, p. 45) consideram,

[...] uma subjetividade essencialmente fabricada, modelada, recebida e consumida que, por sua vez, ultrapassa os níveis da produção e do consumo e atinge o próprio inconsciente dos indivíduos. Isto quer dizer que tudo aquilo que acontece mesmo quando sonhamos, fantasiamos ou nos apaixonamos, são afetos produzidos, socialmente, pelo capitalismo moderno e estão diretamente relacionados com o modo dos indivíduos perceberem o mundo, de se "modelizarem" os comportamentos e de se articularem as suas relações sociais. 
Em relação à estética do corpo, Braga (2015, p. 18) reforça que os conceitos de beleza, que são construídos num determinado momento histórico, desfazem-se em momentos seguintes. Porém, acrescentase, com base nos fundamentos teóricos de Foucault (2015), que tais conceitos realmente se ressignificam, mas são sempre construídos e conduzidos por poderes que garantem a manutenção das normas que disciplinam os corpos. Como acentua esse autor:

[...] o corpo composto de sólidos e comandado por movimentos, cuja imagem tanto povoara os sonhos dos que buscavam a perfeição disciplinar. Esse novo objeto é o corpo natural, portador de forças e sede de algo durável; é o corpo suscetível de operações especificadas, que têm sua ordem, seu tempo, suas condições internas, seus elementos constituintes. O corpo, tornando-se alvo dos novos mecanismos do poder, oferece-se a novas formas de saber (FOUCAULT, 1999, p. 132).

Voltando ao papel que se inscreve em práticas discursivas da publicidade, no processo de disciplinamento dos cachos, reafirma-se que é por meio do discurso desta ferramenta, muitas vezes aliada a canais midiáticos, que a cultura de disciplinamento dos cabelos é difundida e fortificada. Uma vez consolidada, essa cultura, segundo Lazzarotto e Rossi (2004, p. 18): "Torna-se novos "Cavalos de Tróia", dados como presentes, mas carregando dentro de si o veneno que contaminará as mentes e os corações de inúmeras populações, sem defesa e sem resistência".

Para promover a disciplina dos cachos, considera-se que o poder inscrito na publicidade utiliza meios que levam a mulher de cabelos cacheados a aceitar, passivamente, o discurso de disciplinamento dos cabelos e ainda considere que seguir as instruções para isso seja o correto.

Assim, as técnicas de disciplinamento dos cabelos cacheados, elaboradas pela indústria de beleza capilar, e reforçadas pela publicidade, com todas suas técnicas de persuasão, são aceitas e aplicadas por um número significativo de mulheres afro-brasileiras. É uma estratégia que induz tanto à compra dos produtos, quanto ao desejo de adquirir uma desejável aparência.

\section{Conclusão}

Neste trabalho, analisou-se uma série enunciativa composta de quatro anúncios, que promovem cabelos cacheados, buscando-se entender normas de beleza dos cabelos produzidas em enunciados 
V. 8 (2)

$120-136$

mai/ago 2018 verbais. Articularam-se alguns estudos de Michel Foucault (1999) sobre o poder disciplinar e sua inscrição nos corpos dos indivíduos e discursos (FOUCAULT, 2012).

Na visão de Michel Foucault, as práticas sociais de uma época resultam de discursos eivados de poderes, que se pulverizam e constituem o sujeito, em todos os níveis da sua existência, inclusive em seus corpos. Com Gomes (2006, p. 264) viu-se que o corpo pode ser ordenado em suas diferentes dimensões, entre elas, o cabelo. Assim, percebeu-se que práticas sociais (discursivas e não discursivas) que definem o que é um cabelo bonito não fogem dessa articulação entre disciplina, poder e corpo.

Mobilizaram-se pesquisas que comprovam a manipulação do cabelo como forma de disciplinamento do corpo, desde períodos remotos, como no Antigo Egito.

Na atualidade, a indústria de cosméticos capilar e a publicidade assemelham-se a um grande "laboratório de manipulação do comportamento humano", expressão usada por Guareschi (2004), pois produzem sentimentos e valores, valendo-se das frustrações e inseguranças que os indivíduos adquirem, historicamente, perante a exigência social de perfeição do corpo. A publicidade faz com que uma mulher, um homem, uma criança, um idoso estejam sempre em busca de uma vida e um corpo ideal, aceitável e admirável.

Nesse sentido, considera-se que os anúncios de produtos para cabelos cacheados fabricam na mulher afrodescendente o desejo de aceitação, de encantamento, de sedução, de conquista do padrão exigido. Assim, concebe-se que o discurso da publicidade é um discurso de controle social. Com a indústria, ela constrói o tipo ideal de consumidor, conduz normas de comportamento, operando na vida cotidiana, disciplinando a visão de mundo dos indivíduos, sua existência.

Neste estudo, contatou-se que o disciplinamento dos cabelos de mulheres afrodescendentes se pauta em discursos que implicitamente sugerem que a estética natural dos cabelos cacheados não é ideal, é inferior, e deve ser reestruturada, caso contrário, as mulheres com esse tipo de cabelo, que não seguem as "orientações" da indústria de cosméticos, correm o risco de serem rejeitadas pela sociedade. Esse disciplinamento age com base em uma memória, ainda muito viva na cultura brasileira, que propõe como referência adequada de beleza capilar as formas dos cabelos lisos, principalmente do liso de matriz cultural branca. 


\section{Referências}

BRAGA, Amanda Batista. A mídia impressa na promoção de discursos sobre políticas de igualdade racial: o negro e a revista Raça. 2008. 112 f. Dissertação (Mestrado em Linguística) - Universidade Federal de São Carlos - UFSCar, São Carlos, 2008. Disponível em: <https://repositorio.ufscar.br/handle/ ufscar/5663>. Acesso em: 22 nov. 2015.

BRAGA, Amanda. História da beleza negra no Brasil: discursos, corpos e práticas. São Carlos: EdUFSCar, 2015.

CZERMAK, Rejane; SILVA, Rosane Azevedo Neves da. Comunicação e produção da subjetividade. In: GUARESCHI, Pedrinho Arcides (Org.). Comunicação e controle social. 6. ed. Petrópolis: Vozes, 2004. cap.4.

FOUCAULT, Michel. Vigiar e Punir. 20. ed. Petrópolis: Vozes, 1999.

FOUCAULT, Michel. A arqueologia do saber. 8. ed. Rio de Janeiro: Forense, 2012.

FOUCAULT, Michel. Microfísica do poder. 3. ed. Rio de Janeiro: Paz \& Terra, 2015.

GOMES, Nilma Lino. Sem perder a raiz: corpo e cabelo como símbolos da identidade negra. 2. ed. Belo Horizonte: Autêntica, 2008.

GUARESCHI, Pedrinho A. A realidade da comunicação: visão geral do fenômeno. In: (Org.). Comunicação e controle social. 6. ed. Petrópolis: Vozes, 2004. cap.1.

LAZZAROTTO, Gisley Romanzini; ROSSI, Janete Schaeffer. Comunicação, Gestalt e Behaviorismo. In: GUARESCHI, Pedrinho Arcides (Org.). Comunicação e controle social. Petrópolis: Vozes, 2004. cap.2.

OLINTO, Antonio. Novo Dicionário Ilustrado de Inglês: Inglês-Português, Português-Inglês. São Paulo: DCL, 2008.

ORTEGA, Francisco. O corpo em Foucault entre construtivismo e fenomenologia. In: BAGRICHEVSKY, Marcos; ESTEVÃO, Adriana; PALMA, Alexandre (Org.). A saúde em debate na educação física. Ilhéus: Editora da UESC, 2007. p. 39-75.

QUINTÃO, Adriana Maria Penna. 0 que ela tem na cabeça?: um estudo sobre o cabelo como performance identitária. 2013. 196 f. Dissertação (Mestrado em Antropologia) - Universidade Federal Fluminense, Niterói, 2013. Disponível em: <www.uff.br/.../O-QUE-ELA-TEM-NA-CABECA_Um-estudo-sobre-ocabelo-como performance-identitária>. Acesso em: 25 de nov. de 2015.

SANTOS, Patrícia; MARTINS, Geiza. A história do alisamento através das décadas. Revista Cabelos\&Cia. São Paulo, 26/12/2015. Disponível em: <http:// revistacabelos.uol.com.br/a-historia-do-alisamento-atraves-das-decadas $>$. Acesso em: 17 de jul. 2017.

THOMPSON, John Brookshire. A mídia e a modernidade: uma teoria social da mídia. 11. ed. Petrópolis: Vozes, 2009.

VAUGHAN, Patrícia Anne. A imagem americana de beleza física e as mudanças provocadas pelo "Black Power" na década de 60. Revista de Letras, Fortaleza, 
V. $8(2)$ $120-136$ mai/ago 2018

v. 1/2, n. 22, p. 59-62, jan/dez. 2000. Disponível em: <www.revistadasletras. ufc/rl22Art08.pdf.>. Acesso em: 20 de jul. 2017.

VIEIRA, Adriane; SOUZA, Jorge Luiz de. A moralidade implícita no ideal de verticalidade da postura corporal. Rev. Bras. Cienc. Esporte, Campinas, v. 23, n. 3, p. 133-148, mai. 2002. Disponível em: <www.revista.cbce>. Acesso em: 17 de jul. 2017. 